\title{
Model Pengelolaan Kepiting Bakau untuk Kelestarian Habitat Mangrove di Taman Nasional Kutai Provinsi Kalimantan Timur
}

\author{
Nirmalasari Idha Wijaya ${ }^{\text {a*}}$, Fredinan Yulianda ${ }^{\text {b }}$ \\ ${ }^{a}$ Universitas Hang Tuah, Jl. Arief Rahman Hakim No.150 Surabaya \\ ${ }^{b}$ Institut Pertanian Bogor, Jl. Agathis, Kampus IPB Bogor \\ *Email: nirmalasari@hangtuah.ac.id
}

Diterima (received) 20 Februari 2018; disetujui (accepted) 31 Januari 2019; tersedia secara online (available online) 1 Februari 2019

\begin{abstract}
The National Park Kutai (TNK) has \pm 5.227 ha mangrove forest in along coastal beach. Therefore , almost $23 \%$ of mangrove forest was degraded effect to land conversion and utilization of damaged. Mud crab (Scylla serrata) is one of the resources in mangrove ecosystem, thus can be utilized for the cultivation sylvofishery. The Utilization was an alternative livelihood for the local resident in TNK areas that was not damaged their forest necessity. The model of sylvofishery utilization mud crab prepared were 5 sub-models, such as mangrove habitat sub-model, catching Mud Crab sub-model, enlargement cultivation of mud crab sub-model, market sub-model, social sub-model. The simulation results of the dynamic model, was showed optimistic of scenario performance model to sustainable for management of mangrove forest in The TNK thus conducted with optimization approached resources in utilization of Scylla serrata. With silvofishery expected balance between utilization and conservation of mangrove ecosystems.
\end{abstract}

Keywords: Dynamic model; management; Mud crab (Scylla serrata); mangrove forest

\begin{abstract}
Abstrak
Taman Nasional Kutai $(\mathrm{TNK})$ memiliki \pm 5.227 ha hutan mangrove di sepanjang pesisir pantainya. Hampir 23\% luas hutan mangrove ini mengalami degradasi akibat konversi lahan dan pemanfaatan yang merusak. Kepiting bakau merupakan salah satu sumberdaya yang terdapat dalam ekosistem mangrove, yang dapat dimanfaatkan untuk budidaya sylvofishery. Pemanfaatan ini merupakan mata pencaharian alternatif bagi penduduk lokal dalam kawasan TNK agar dapat memenuhi kebutuhan hidupnya tanpa merusak hutan mangrove. Model pemanfaatan sylvofishery kepiting bakau disusun dari 5 submodel, yaitu habitat mangrove, penangkapan kepiting, budidaya pembesaran kepiting, pasar, dan sosial. Hasil simulasi terhadap model dinamik, menunjukkan bahwa skenario optimistik memberikan kinerja model yang lebih berkelanjutan untuk pengelolaan hutan mangrove di TNK, bila dilakukan dengan pendekatan optimasi pemanfaatan sumberdaya Scylla serrata. Dengan sylvofishery diharapkan terjadi keseimbangan antara pemanfaatan dan kelestarian lingkungan hutan mangrove.
\end{abstract}

Kata Kunci: model dinamik; pengelolaan; kepiting bakau; hutan mangrove

\section{Pendahuluan}

Hutan mangrove merupakan habitat utama bagi S. serrata. Populasi kepiting bakau secara khas berasosiasi dengan hutan mangrove yang masih baik, sehingga hilangnya habitat akan memberikan dampak yang serius pada populasi kepiting. Keberlanjutan pengembangan budidaya kepiting sangat memerlukan integrasi antara perikanan dengan pengelolaan mangrove. Status ekologi kepiting bakau yang berhubungan dengan biologi populasi dan pengelolaannya perlu dipahami untuk mendukung pengembangan dari perikanan dan budidaya kepiting bakau yang berkelanjutan (LeVay 2001).

doi: https://doi.org/10.24843/blje.2019.v19.i01.p01

(c) 2019 by the authors; Content from this work may be used under the terms of the Creative Commons Attribution 3.0 licence. Any further distribution of this work must maintain attribution to the author(s) and the title of the work, journal citation and DOI. Published under licence by Udayana University, Indonesia. 
Untuk meminimalisasi rusaknya ekosistem mangrove diperlukan pengembangan model pengelolaan mangrove yang melibatkan masyarakat dalam kawasan tersebut, karena keberadaan masyarakat sekitar hutan mangrove sangat berpengaruh terhadap kelestarian ekosistem hutan mangrove. Peran serta masyarakat yang meluas dan tidak sekadar simbolik ternyata menunjukkan hasil yang baik yaitu produktifitas tercapai tanpa menyampingkan kepentingan kelestarian lingkungan dan eksistensi masyarakat lokal. Kolaborasi dengan masyarakat lokal merupakan kebutuhan dan keharusan, karena tujuan produksi dan pelestarian dapat dicapai secara lebih efektif dan pada saat yang sama tercipta suatu mekanisme resolusi konflik yang interaktif dan dialogis (PHKA-Dephut et al. 2002).

Model pengelolaan ekosistem mangrove di salah satu desa dalam kawasan TNK sudah pernah diteliti oleh Gunawan et al. (2005) yang melakukan penelitian tentang Model Pelestarian Ekosistem Mangrove di Kawasan Taman Nasional Kutai oleh Masyarakat Dusun Teluk Lombok, namun dalam penelitian ini model yang dihasilkan hanya berupa deskripsi tentang pelaksanaan pengelolaan mangrove yang telah rusak/dibuka di kawasan tersebut oleh masyarakat bersama dengan LSM Bikal.

Pada penelitian ini akan disusun model pengelolaan zona pemanfaatan hutan mangrove di kawasan TNK, yang berbasis pada pemanfaatan sumberdaya S. serrata, sebagai biota yang mempunyai keterkaitan habitat dengan hutan mangrove. Penelitian ini dilakukan secara komprehensif dengan pendekatan sistem dinamik yang didukung oleh data bioekologi kepiting bakau dan daya dukung lingkungan. Data bioekologi kepiting bakau dikumpulkan melalui pencatatan data hasil tangkapan selama 8 bulan. Data biekologi ini akan digunakan secara menyeluruh melalui metode analisis sistem dinamik untuk menyusun rencana pengelolaan sumberdaya kepiting bakau. Hasil dari analisis sistem berupa model pengelolaan kepiting bakau, akan mempunyai karakter yang berbeda dengan kebijakan pengelolaan kepiting bakau di perairan umum, karena memasukkan variabel aturan-aturan dalam pengelolaan kawasan konservasi.

Tujuan penelitian ini adalah memberikan masukan rekomendasi kebijakan atau perubahan legislasi mengenai pengelolaan kolaboratif yang berbasis ilmiah sehingga walaupun pemanfaatan sumberdaya alam bakau dapat dilakukan namun tujuan utama pengelolaan taman nasional untuk konservasi keanekaragaman hayati tetap dapat dipertahankan.

\section{Metode Penelitian}

\subsection{Waktu dan Lokasi Penelitian}

Penelitian dilakukan di kawasan mangrove di Taman Nasional Kutai (TNK) seluas 5277.79 ha (Gambar 1). Waktu pengambilan data antara bulan Oktober 2009- Juni 2010.

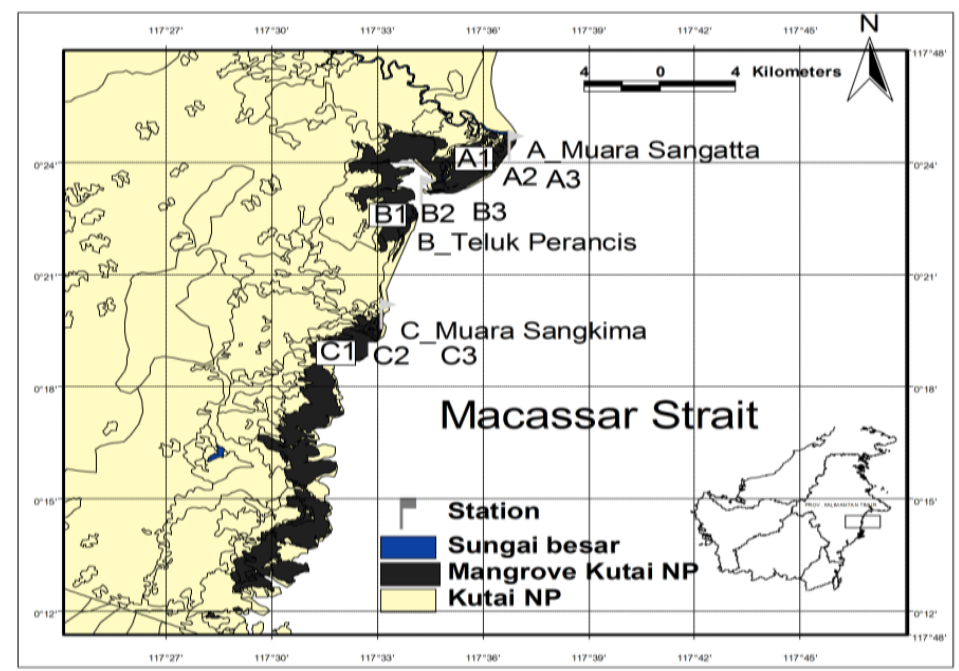

Gambar 1. Peta lokasi penelitian. 


\subsection{Pemodelan dan Simulasi Sistem Pengelolaan S. serrata}

Tahapan pemodelan diuraikan ke dalam dua bagian, yaitu aspek konseptual dan aspek teknis. Bagian konseptual merupakan masukan dari strukturisasi sistem yang telah difiltrasi. Alur pemodelan digambarkan pada Gambar 2.

Membangun struktur model untuk memudahkan secara visual bagi pengguna model dalam memahami dan menangkap hipotesis dinamis yang dimaksud dengan menggunakan alat CLD (Causal Loop Diagram). Secara konseptual, pada bagian awal bab ini telah dibangun diagram sebab akibat (CLD) sistem pengelolaan kepiting bakau di TNK. Kemudian, struktur model dilanjutkan dengan membangun diagram alir dengan alat SFD untuk mengantarkan pada tahap simulasi. Sebelum membangun diagram alir, harus dipahami dahulu variabel atau parameter yang akan dijadikan stock (akumulasi) dan flow (aliran) yang dapat mengubah nilai stock (Ford, 1999).

Tahap selanjutnya setelah pembuatan diagram stock flow (SFD) adalah memformulasikan diagram tersebut. Tahap formulasi model simulasi menggunakan alat bantu program komputer Powersim Studio 2005. Model simulasi harus sudah dilengkapi dengan persamaan matematis yang benar, parameter dan penentuan kondisi nilai awal (initial) agar dapat dijalankan (run). Powersim pertama kali menghitung nilai awal untuk mengukur stock dan aliran sebuah flow. Kemudian flow digunakan untuk memperbaharui stock tersebut. Nilai baru stock digunakan kembali untuk menghitung dan seterusnya seiring dengan perubahan waktu secara berulang.

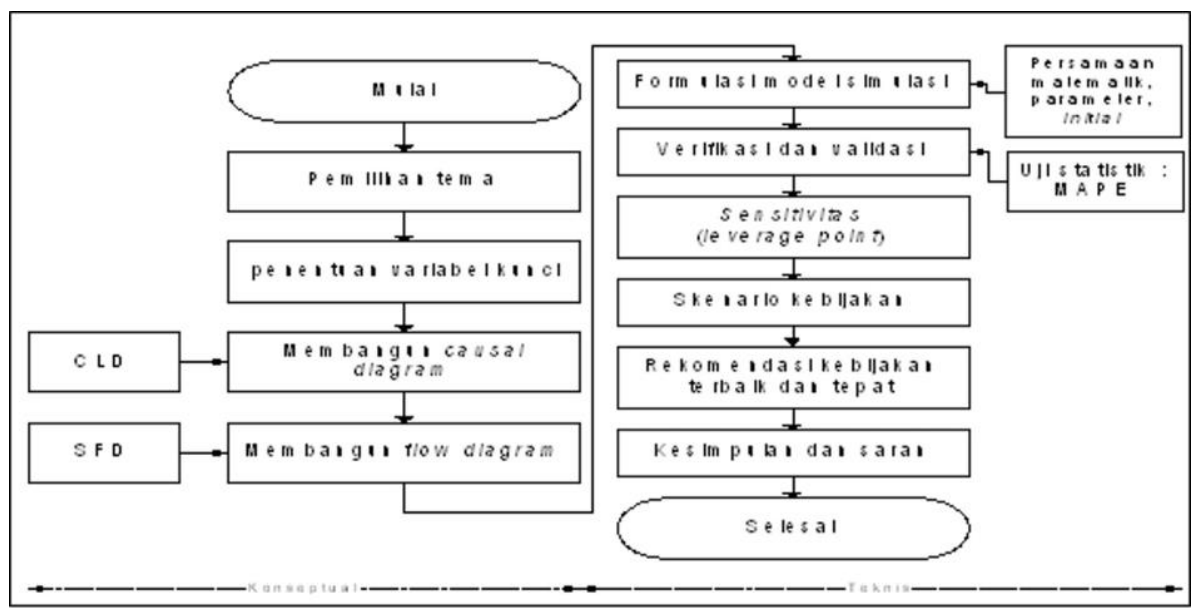

Gambar 2. Alur tahapan pemodelan pengelolaan Scylla serrata. (modifikasi Rohmatullah, 2008)

\subsection{Membangun Diagram Kausal dan Diagram Alir}

Model pemanfaatan kepiting bakau disusun dari 5 submodel, yaitu submodel habitat mangrove, submodel penangkapan kepiting, submodel budidaya pembesaran kepiting, submodel pasar, dan submodel sosial.

\section{Hasil dan Pembahasan}

\subsection{Model Pengelolaan S. serrata}

Model pengelolaan sumberdaya S. serrata dikembangkan melalui dinamika interkoneksi antar parameter kunci seiring dengan perubahan waktu dari sistem ekologi-ekonomi-sosial yang dikaji dalam penelitian ini. Konsep dasar perumusan model mengacu pada efek berantai, dimana terjadinya perubahan dalam parameter pengelolaan dapat mempengaruhi sistem keberlanjutan pengelolaan sumberdaya $\mathrm{S}$. serrata. 


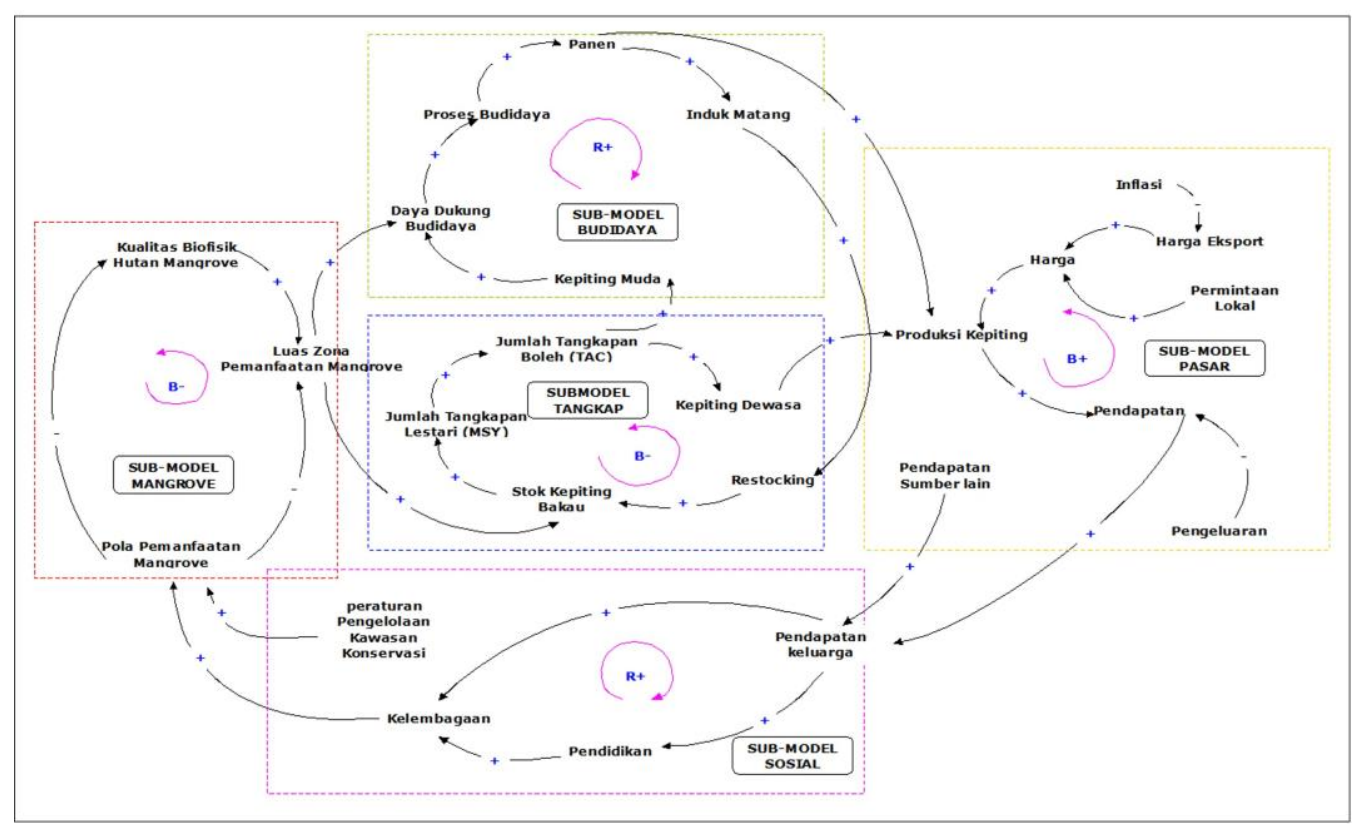

Gambar 3. Diagram kausal model konseptual pemanfaatan kepiting bakau di kawasan mangrove TNK.

Perumusan dalam model yang dibangun didasarkan pada model matematika sederhana. Perangkat lunak yang digunakan untuk merumuskan model yang dibangun dalam penelitian ini yakni Powersim Studio 2005. Selanjutnya model pengelolaan sumberdaya Scylla serrata ini disebut dengan model CRASYMAN (Crab Sylvofishery Management).

Langkah awal pengembangan model pengelolaan sumberdaya S. serrata di habitat mangrove TNK adalah merumuskan model secara matematis, lalu memasukkan nilai-nilai parameter yang diperoleh pada analisis sebelumnya ke dalam model yang dibangun dan terakhir dilakukan analisis model.

Nilai-nilai atribut yang digunakan untuk membangun dan menganalisis model keberlanjutan pengelolaan sumberdaya S. serrata di habitat mangrove TNK disajikan pada Tabel 1 dan diagram causal model konseptual disajikan pada Gambar 3.

Tabel 1. Nilai dugaan parameter pada model pengelolaan sumberdaya S. serrata di habitat mangrove TNK

\begin{tabular}{|c|c|c|}
\hline Submodel dan Parameter & Nilai Dugaan & Keterangan \\
\hline \multicolumn{3}{|l|}{ I submodel mangrove } \\
\hline 1. Initial luasan mangrove (ha) & $5.277,79$ & Hasil analisis citra Terra Aster 2005 \\
\hline 2. Laju perluasan mangrove (ha/th) & & $\operatorname{var} 7-\operatorname{var} 6$ \\
\hline 3. Penebangan kayu mangrove (ha/th) & 12,25 & Analisis trend/rata-rata \\
\hline 4. Perluasan pemukiman (ha/th) & 13 & Analisis trend/rata-rata \\
\hline 5. Pembukaan tambak (ha/th) & 10 & Analisis trend/rata-rata \\
\hline 6. Laju konversi mangrove (ha/th) & & $\operatorname{var} 3+\operatorname{var} 4+\operatorname{var} 5$ \\
\hline 7. Pertambahan luas mangrove (ha/th) & 0,257 & $\operatorname{var} 1 * \operatorname{var} 9$ \\
\hline 8. Zona pemanfaatan mangrove (ha) & $1.028,85$ & $\operatorname{var} 1 * \operatorname{var} 10$ \\
\hline 9. Konstanta pertambahan luas (\%/th) & 0,05 & Data sekunder (Laju akresi) \\
\hline $\begin{array}{l}\text { 10. Konstanta fraksi zona pemanfaatan } \\
\text { mangrove }(\%)\end{array}$ & 20 & Dahuri dkk. (2004) \\
\hline $\begin{array}{l}\text { 11. Habitat Suitability Index (HSI) (tanpa unit } \\
\text { satuan/TS) }\end{array}$ & 0,622 & $\begin{array}{l}\text { Hasil Analisis HSI (Olah Data Primer } \\
\text { 2009) }\end{array}$ \\
\hline
\end{tabular}




\begin{tabular}{|c|c|c|}
\hline Submodel dan Parameter & Nilai Dugaan & Keterangan \\
\hline \multicolumn{3}{|l|}{ II Submodel Penangkapan S. serrata } \\
\hline 13. Potensi S. serrata $(\mathrm{kg} / \mathrm{th})$ & $22.192,43$ & $\begin{array}{l}\text { Analisis Deskriptif (0lah Data Primer } \\
\text { 2009) }\end{array}$ \\
\hline $\begin{array}{l}\text { 14. Produksi tangkapan S. serrata per tahun } \\
(\mathrm{kg} / \mathrm{th})\end{array}$ & 6.800 & $\begin{array}{l}\text { Analisis Deskriptif (series data diolah } \\
\text { 2005-2009) }\end{array}$ \\
\hline 15. Laju potensi S. serrata & $18.488,80$ & \\
\hline 16. Laju eksploitasi faktual (TS) & 0,556 & $\mathrm{Z} / \mathrm{F}$ \\
\hline 17. $\mathrm{Z}=$ total laju mortalitas $(\mathrm{TS})$ & 2,41 & $\begin{array}{l}\text { Hasil olahan FISAT (0lah Data Primer } \\
\text { 2009) }\end{array}$ \\
\hline 18. $\mathrm{M}=$ laju mortalitas alami (TS) & 1,07 & $\begin{array}{l}\text { Hasil olahan FISAT (0lah Data Primer } \\
\text { 2009) }\end{array}$ \\
\hline 19. $\mathrm{F}=$ laju mortalitas penangkapan $(\mathrm{TS})$ & 1,34 & Var $17-\operatorname{var} 18$ \\
\hline 20. Fraksi pengaturan tangkap $(\%)$ & 100 & Asumsi kebijakan penangkapan $100 \%$ \\
\hline 21. Rerata eksploitasi maksimal (TS) & 0,455 & $\begin{array}{l}\text { Hasil olahan FISAT (0lah Data Primer } \\
\text { 2009) }\end{array}$ \\
\hline 22. Stok total S. serrata $(\mathrm{kg} / \mathrm{th})$ & $10.030,98$ & $\operatorname{var} 13 * \operatorname{var} 21$ \\
\hline 23. Stok tangkapan S. serrata $(\mathrm{kg} / \mathrm{th})$ & $4.011,96$ & Stok total - stok benih \\
\hline 24. Rerata kelimpahan S. serrata (kg/ha.th) & 43,1 & $\operatorname{var} 13$ / var 1 \\
\hline \multicolumn{3}{|l|}{ III Submodel Budidaya S. serrata } \\
\hline 25. Jumlah unit karamba (unit) & 490 & var 12 / var 25 \\
\hline 26. Konstanta padat tebar benih/unit (kg/unit) & 30 & Diacu dari Triño \& Rodriguez (2002) \\
\hline 27. Stok benih untuk budidaya (kg/th) & $6.018,59$ & $\operatorname{var} 22 * \operatorname{var} 28$ \\
\hline 28. Fraksi stok benih (\%) & 60 & Scientist judgement \\
\hline 29. Ketersediaan benih budidaya (kg/unit) & 60 & var 27 / var 25 \\
\hline 30. SR budidaya (TS) & 0,76 & Hasil analisis data primer 2010 \\
\hline 31. Konversi biomass per ekor (ekor/kg) & 4 & Hasil analisis data primer 2010 \\
\hline 32. Panen budidaya (ekor/th ) & 117.884 & $\operatorname{Var} 29 * \operatorname{var} 30 * \operatorname{var} 31$ \\
\hline 33. Fraksi restoking induk (\%) & 1 & Diacu dari Warner (1977) \\
\hline 34. Restoking induk S. serrata (ekor/th) & 1.167 & $\operatorname{var} 33^{*}$ var 34 \\
\hline 35. Produksi budidaya (ekor/th) & 116.705 & $\operatorname{var} 32-\operatorname{var} 34$ \\
\hline konversi produksi bddy (kg/th) & $29.176,25$ & \\
\hline 36. Total biaya budidaya (IDR/th) & 452.197 .398 & $\operatorname{var} 37+\operatorname{var} 38+\operatorname{var} 39$ \\
\hline 37. Biaya benih (IDR/th) & 177.197 .398 & Hasil analisis data primer 2010 \\
\hline 38. Biaya Tenaga Kerja (TK) (IDR/th) & 150.000 .000 & Hasil analisis data primer 2010 \\
\hline 39. Biaya pakan (IDR/th) & 125.000 .000 & Hasil analisis data primer 2010 \\
\hline \multicolumn{3}{|l|}{ IV submodel ekonomi } \\
\hline 40. Harga ekspor S. serrata (IDR/kg) & 35.000 & Hasil analisis data 2010 \\
\hline 41. Biaya penangkapan $(\%)$ & 30 & Asumsi \\
\hline $\begin{array}{l}\text { 42. Keuntungan penangkapan S. serrata } \\
\text { (IDR/th) }\end{array}$ & 84.251 .133 & $\left(\operatorname{var} 23^{*} \operatorname{var} 40\right)-\operatorname{var} 41$ \\
\hline 43. Keuntungan budidaya S. serrata (IDR/th) & 568.971 .352 & $\left(\operatorname{var} 35^{*} \operatorname{var} 40\right)-\operatorname{var} 36$ \\
\hline 44. Keuntungan total (IDR/th) & 653.222 .485 & $\operatorname{var} 42+\operatorname{var} 43$ \\
\hline \multicolumn{3}{|l|}{ V submodel sosial } \\
\hline 45. Potensi jumlah pembudidaya (KK) & 60 & Hasil analisis kuisioner 2009 \\
\hline 46. Pendapatan keluarga (IDR/th) & & $(\operatorname{var} 44 / \operatorname{var} 45)+\operatorname{var} 47$ \\
\hline 47. Pendapatan sumber lain (IDR/th) & 500.000 & Asumsi \\
\hline 48. Fraksi dana pendidikan $(\%)$ & 15 & Hasil analisis kuisioner 2009 \\
\hline 49. Alokasi dana pendidikan (IDR/th) & 1.703 .740 & $\operatorname{var} 46^{*} \operatorname{var} 48$ \\
\hline $\begin{array}{l}\text { 50. Pengaruh dana pendidikan terhadap } \\
\text { pengetahuan masyarakat (TS) }\end{array}$ & & Hasil analisis regresi berdasarkan asumsi \\
\hline $\begin{array}{l}\text { 51. Pengaruh pengetahuan terhadap peningkatan } \\
\text { kesadaran lingkungan }(\%)\end{array}$ & & Asumsi \\
\hline
\end{tabular}




\subsection{Submodel mangrove}

Submodel mangrove menggambarkan dinamika meningkat/menurunnya luasan dan kualitas hutan mangrove di TNK. Submodel dibangun dari elemen luas mangrove, zona pemanfaatan mangrove, laju perluasan mangrove yang dipengaruhi oleh laju konversi dan laju penambahan luas mangrove, kondisi habitat yang mempengaruhi indeks kesesuaian lingkungannya (HSI), dan pengaruh tingkat kesadaran lingkungan terhadap konversi mangrove. Semua peubah-peubah ini diformulasikan secara numerik menghasilkan diagram alir stok submodel mangrove seperti diperlihatkan pada Gambar 4.

Initial (luas awal) habitat mangrove ditentukan berdasarkan hasil analisis Citra Terra Aster Tahun 2005, yaitu seluas 5.277,779 ha. Adanya pemanfaatan mangrove untuk penggunaan lain, yaitu menjadi tambak, perluasan pemukiman, dan penebangan pohon mangrove, telah menyebabkan terjadi konversi mangrove. Untuk itu perlu adanya perbaikan pola pemanfaatan mangrove yang merusak (mengkonversi mangrove) agar laju konversi ini dapat diturunkan, bahkan bila perlu tidak terjadi konversi mangrove lagi.

Kesadaran lingkungan dalam bentuk pengelolaan berbasis ekosistem yang diasumsikan semakin meningkat dengan adanya peningkatan pengetahuan melalui pendidikan formal, akan mempengaruhi pola pemanfaatan mangrove oleh masyarakat pembudidaya. Bila semula menggunakan mangrove untuk membuka tambak, maka selanjutnya akan menggunakan mangrove sebagai lahan budidaya kepiting bakau, sehingga tidak perlu membuka mangrove lagi. Olsen dalam UNEP (2006) menyatakan pengelolaan berbasis ekosistem diharapkan terjadi perubahan perilaku, meliputi: perubahan perilaku pada kelembagaan dan kelompok stakeholder, perubahan perilaku sehubungan dengan efektivitas pemanfaatan sumberdaya, dan perubahan dalam strategi investasi.

Luas zona pemanfaatan mangrove merupakan implikasi dari kebijakan yang mengijinkan adanya pemanfaatan terbatas di kawasan Taman Nasional Kutai. Kebijakan ini dapat berupa persentase kawasan TN yang akan dialokasikan untuk pemanfaatan. Interfensi kebijakan ini sangat besar pengaruhnya dalam pola pemanfaatan mangrove, karena akan mempengaruhi besarnya daya dukung kawasan, pada penelitian ini daya dukung kawasan adalah untuk pemanfaatan budidaya sylvofishery. Sylvofishery menyediakan alternatif aktivitas ekonomi bagi rakyat pedesaan yang miskin dan hal itu mungkin dapat mengurangi tekanan ekologi terhadap hutan mangrove (Arifin, 2006).

Selain luasnya zona pemanfaatan, daya dukung budidaya sylvofishery juga sangat dipengaruhi oleh kualitas lingkungan, yang digambarkan dengan indeks kesesuaian lingkungan (Habitat Suitability Index/HSI). HSI terdiri atas komponen-komponen: kualitas perairan, kualitas tekstur substrat, dan kualitas vegetasi. Bila kondisi lingkungan baik, maka HSI juga akan meningkat. Model HSI digunakan secara meluas sebagai alat dalam pengelolaan spesies, penilaian dampak ekologis, dan penelitian pemulihan ekologi (Duel et al.; Gore \& Hamilton; Maddock dalam Van der Lee et al. 2006).

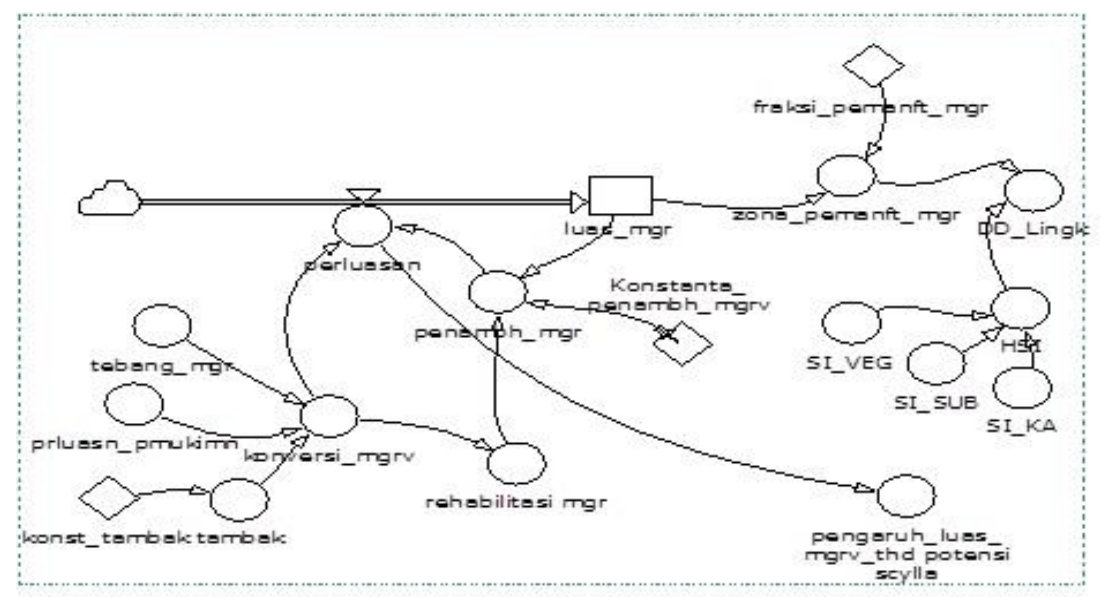

Gambar 4. Diagram alir stok (SFD) submodel habitat mangrove 


\subsection{Submodel Penangkapan S. serrata}

Submodel penangkapan S. serrata menggambarkan dinamika potensi stok S. serrata yang dapat dimanfaatkan untuk perikanan tangkap. Submodel dibangun oleh parameter potensi produksi kepiting bakau, laju eksploitasi faktual dan laju eksploitasi maksimal, laju kematian alami, laju kematian karena penangkapan, stok S. serrata total, kuota tangkapan S. serrata, besarnya restok induk betina, pengaruh luas mangrove terhadap stok S. serrata. Informasi tentang parameter pertumbuhan merupakan hal yang mendasar dalam upaya pengelolaan sumberdaya perikanan. Alasannya adalah karena parameter tersebut dapat memberikan kontribusi dalam menduga produksi, ukuran stok rekruitmen, dan laju kematian (mortalitas) dari suatu populasi.

Analisis pertumbuhan, Plot FordWalford untuk menduga parameter pertumbuhan L $\infty$ dan $\mathrm{K}$ dari persamaan von Bertalanfly. Pendugaan laju eksploitasi S. serrata dilakukan dengan pendugaan laju mortalitas alami (Z) berdasarkan persamaan Beverton dan Holt. Nilai $Z$ dan pendugaan laju mortalitas alami (M) digunakan untuk menduga kematian kepiting bakau akibat penangkapan $(\mathrm{F})=\mathrm{Z}$ M. Selanjutnya laju eksploitasi kepiting bakau (E) dapat diduga dengan menggunakan persamaan: $\mathrm{E}=$ F : Z, nilai Yield per Rekrut (Y/R) untuk menentukan laju eksploitasi maksimal yang diijinkan (Sparre \& Venema, 1999). Diagram alir stok submodel penangkapan S. serrata disajikan pada Gambar 5.

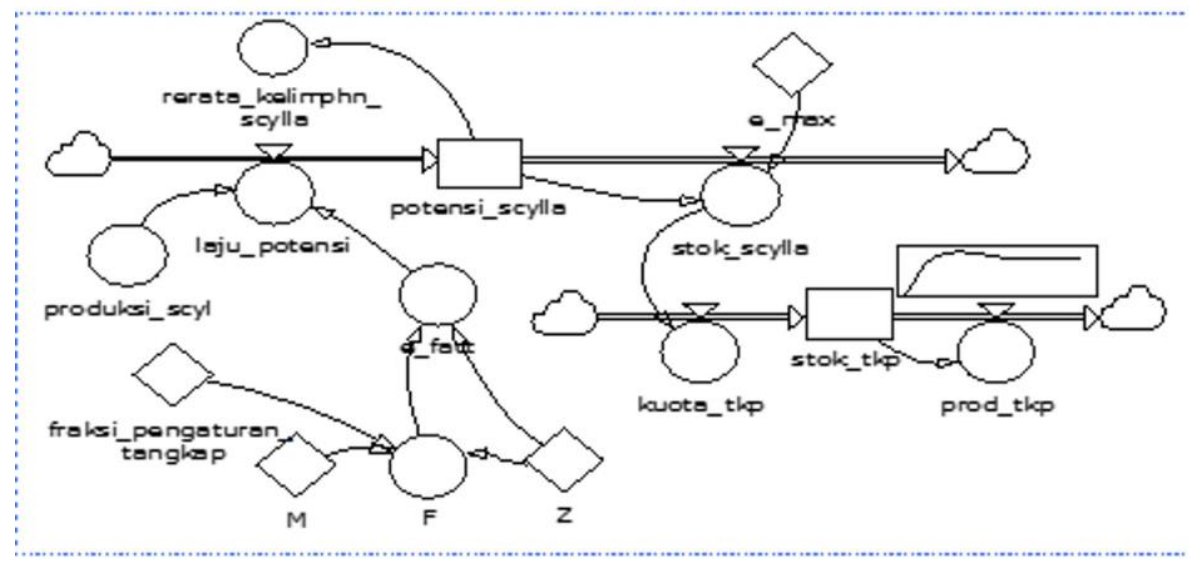

Gambar 5. Diagram alir stok submodel penangkapan S. serrata.

\subsection{Submodel Budidaya Sylvofishery S. serrata}

Submodel sylvofishery terdiri atas elemen daya dukung lingkungan, jumlah unit karamba yang dapat dibangun, berlangsungnya proses budidaya yang dipengaruhi oleh biomassa dan survival rate (SR), elemen panen budidaya, restok induk yang dipengaruhi oleh besarnya fraksi restok, parameter-parameter input produksi yang meliputi biaya benih, tenaga kerja, dan pakan. Semua peubah-peubah ini berhubungan baik secara langsung maupun tidak langsung dan diformulasikan secara numerik menghasilkan diagram alir stok submodel budidaya sylvofishery S. serrata (Gambar 6).

\subsection{Submodel ekonomi S. serrata}

Submodel ekonomi S. serrata menggambarkan dinamika keuntungan yang diperoleh masyarakat bila memanfaatkan sumberdaya S. serrata. Produk kepiting dari hasil tangkapan dan panen budidaya pembesaran kepiting merupakan salah sumber pendapatan bagi masyarakat, namun nilainya sangat tergantung dari harga yang terbentuk di pasar. Asumsinya semakin tinggi harga pasar, maka tingkat pendapatan nelayan/petani akan semakin meningkat. Bila produksi ini dikalikan harga, maka akan diperoleh sebagai keuntungan $(\pi)$. Keuntungan dihitung sebagai Total Revenue (TR) dikurangi Total Cost (TC). 


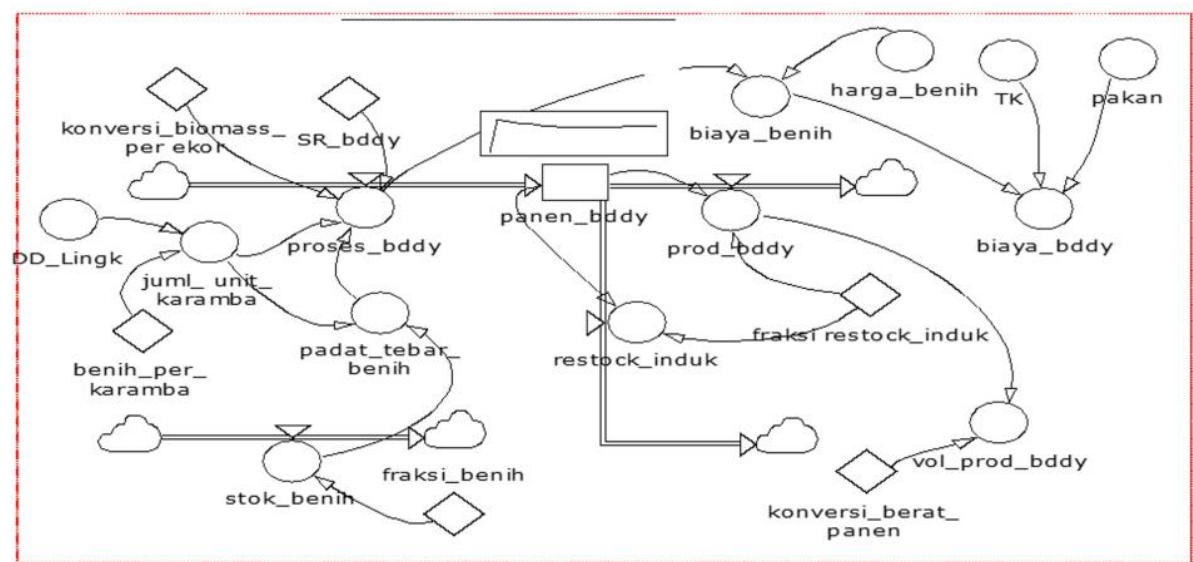

Gambar 6. diagram alir stok submodel budidaya sylvofishery.

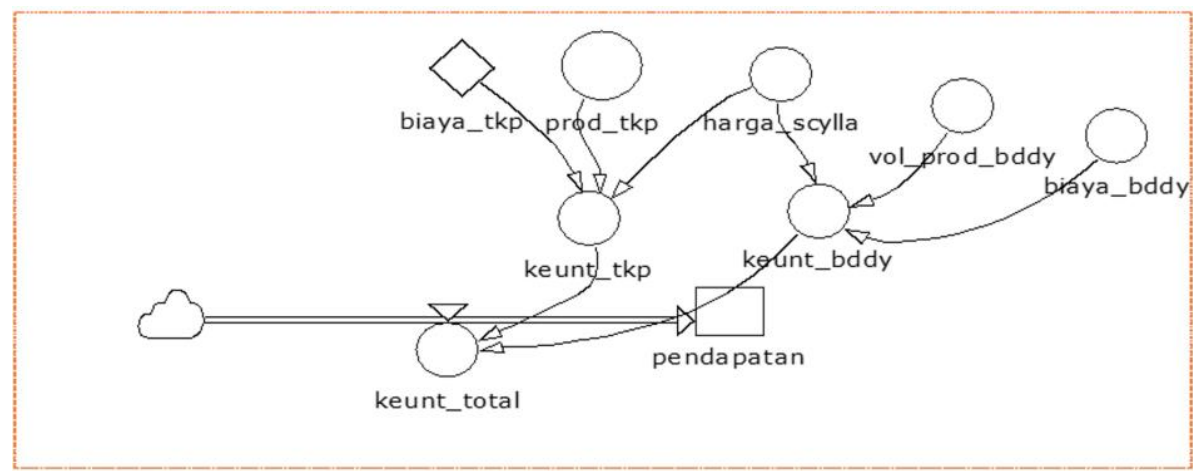

Gambar 7. diagram alir stok submodel ekonomi pada pemanfaatan S. serrata.

Keuntungan total dari pemanfaatan S. serrata merupakan penjumlahan dari keuntungan yang diperoleh dari penangkapan dan keuntungan dari budidaya. Keuntungan total ini juga menjadi pendapatan masyarakat yang diperoleh dari sumberdaya S. serrata. Semua peubah-peubah ini berhubungan baik secara langsung maupun tidak langsung dan diformulasikan secara numerik menghasilkan diagram alir stok submodel ekonomi pemanfaatan S. serrata seperti diperlihatkan pada Gambar 7.

\subsection{Submodel sosial}

Submodel sosial merupakan gambaran dari pengaruh pendapatan terhadap tingkat kesadaran lingkungan masyarakat. Peningkatan pendapatan keluarga akan mempengaruhi tingkat pengetahuan melalui jenjang pendidikan formal. Asumsinya, semakin tinggi jenjang pendidikan formal yang diperoleh, tingkat pengetahuan masyarakat akan semakin meningkat. Selanjutnya tingkat pengetahuan ini akan mempengaruhi kesadaran lingkungan masyarakat yang tinggal di sekitar hutan mangrove TNK dalam pola pemanfaatan ekosistem mangrove. Pola pemanfaatan terhadap sumberdaya mangrove akan berubah sesuai dengan tingkat kesadaran masyarakat dan peraturan perundangan atau kebijakan pemerintah yang berlaku (Gambar 8).

\subsection{Skenario Pengelolaan S. serrata di Habitat Mangrove TNK}

Skenario merupakan suatu alternatif rancangan kebijakan yang dapat dilakukan pada kondisi di lapangan untuk mempengaruhi perilaku parameter pada suatu sistem pemodelan. 


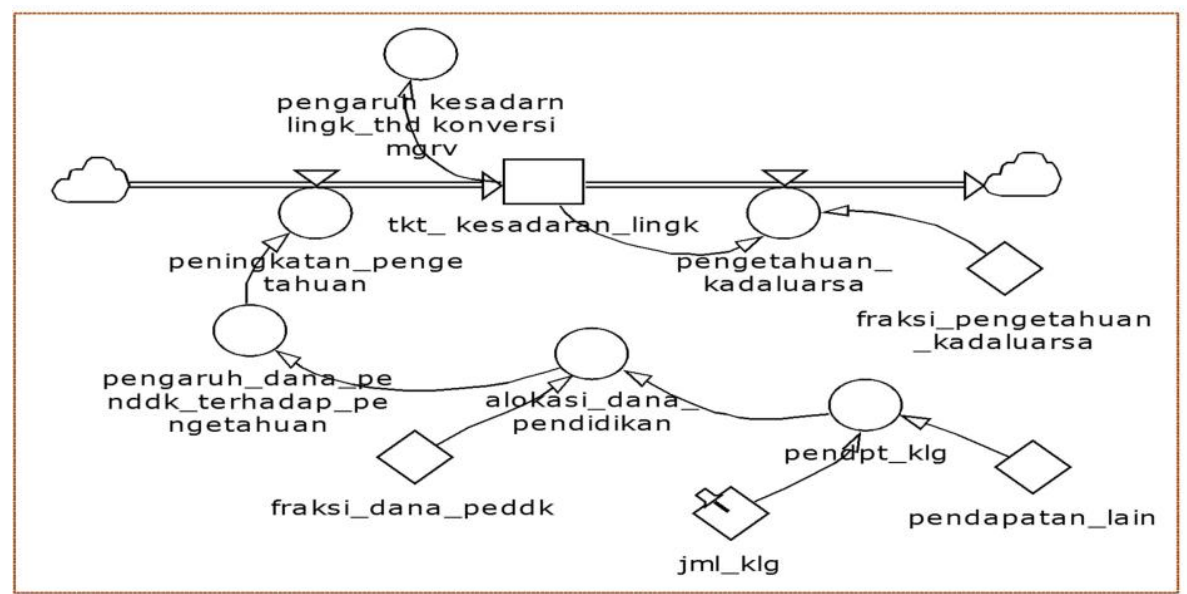

Gambar 8. diagram alir stok submodel sosial pada pemanfaatan S. serrata.

\subsection{Analisis skenario dasar}

Analisis skenario dasar (base case scenario) menguraikan perilaku sumberdaya yang digambarkan oleh parameter luas mangrove, stok S. serrata, panen budidaya sylvofishery, peningkatan pendapatan dari S. serrata, berdasarkan kondisi nyata pada saat ini, hasil analisis terhadap skenario dasar dan simulasi kondisi sampai 20 tahun mendatang (tahun 2010-2030) disajikan pada Gambar 9.

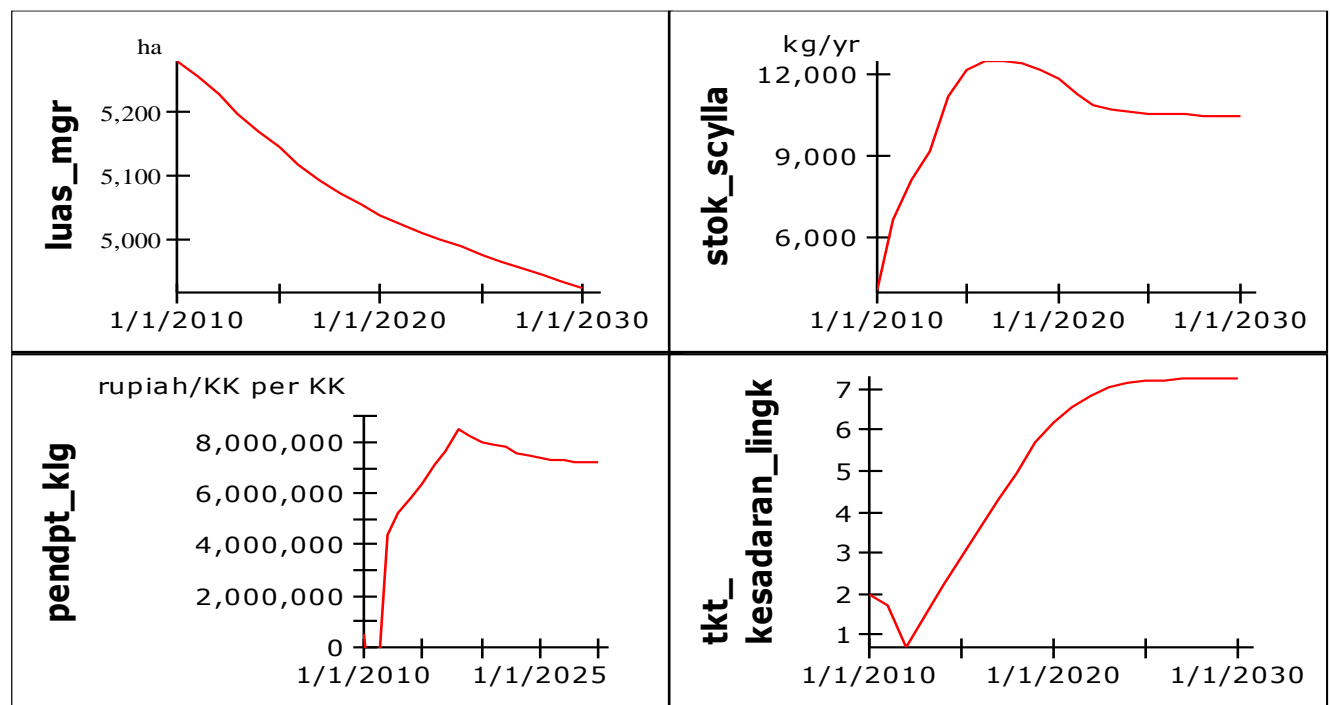

Gambar 9. hasil simulasi skenario dasar pengelolaan S. serrata di TNK.

Gambar 9 menunjukkan bahwa berdasarkan data riil yang disimulasikan hingga 20 tahun ke depan, luasan mangrove cenderung terus menurun. Sementara itu, stok S. serrata masih ada kemungkinan untuk meningkat hingga sekitar tahun 2018, namun setelah itu akan cenderung menurun. Data statistik Dinas Kelautan Kabupaten Kutai Timur menunjukkan hasil tangkapan kepiting bakau secara umum (4 spesies) masih terus meningkat, yaitu pada tahun 2006 sebesar 11,4 ton hingga tahun 2008 menjadi 12,1 ton. Namun demikian penurunan luasan mangrove dan penangkapan kepiting bakau yang tidak terkendali diperkirakan dapat menurunkan stok S. serrata setelah tahun 2018 ke depan. Penurunan stok S. serrata 
ini berpengaruh secara langsung terhadap peningkatan pendapatan masyarakat nelayan, yang juga ikut menurun karena hasil tangkapan menurun. Sehingga dapat dikatakan bila menggunakan skenario dasar, maka pengelolaan sumberdaya di hutan mangrove TNK tidak akan berkelanjutan, baik bagi sumberdaya vegetasi hutan maupun bagi sumberdaya kepiting bakau (S. serrata).

Luas awal habitat mangrove ditentukan dari hasil analisis Citra Terra Aster Tahun 2005, yaitu seluas 5277 ha, Hasil simulasi menggunakan skenario dasar menunjukkan pada tahun 2030 diperkirakan luas mangrove tersebut tersisa 4926.28 ha.

Produksi yang diperoleh pada tahun 2008 pada tingkat eksploitasi faktual 0.556 adalah sebesar 6800 $\mathrm{kg} / \mathrm{th}$. Sehingga potensi S. serrata di habitat mangrove TNK pada tahun 2030 diduga sebesar 22192.43 $\mathrm{kg} / \mathrm{th}$. Potensi S. serrata ini merupakan penurunan dari potensi yang semula sebesar $27374.13 \mathrm{~kg} / \mathrm{th}$. Namun, potensi ini dapat berubah dengan adanya masukan induk dari restoking budidaya sylvofishery, sehingga dalam perhitungan potensi dimasukkan juga input restok induk betina dan pengaruh dari penambahan luas area mangrove.

\subsection{Identifikasi parameter kunci}

Hasil simulasi kinerja model sistem menunjukkan bahwa sistem saat ini memberikan ancaman bagi kelestarian habitat mangrove dan keberlanjutan sumberdaya S. serrata yang ada di dalamnya. Oleh karena itu perlu dirumuskan suatu skenario strategi yang dapat mengendalikan pola pemanfaatan yang merusak habitat mangrove di TNK.

Uji sensitivitas dilakukan untuk memilih parameter kunci, yang berpengaruh besar terhadap berbagai kemungkinan yang akan terjadi di masa yang akan datang. Uji sensitivitas model pada penelitian ini menggunakan parameter yang berpengaruh tinggi terhadap kinerja sistem, yaitu fraksi zona pemanfaatan mangrove (submodel mangrove), fraksi stok untuk benih budidaya (submodel penangkapan), fraksi alokasi dana pendidikan (submodel sosial), dan harga S. serrata (submodel ekonomi).

Metode yang dipakai untuk melihat kepekaan parameter tersebut dengan best-worst case scenario (Sterman 2000). Setiap perubahan parameter, dalam hal ini dinaikkan (diturunkan) sebesar 10\% dari nilai parameter skenario dasar, akan dilihat responnya terhadap perubahan parameter utama. Bila terbukti perubahan pada parameter tersebut mengakibatkan perubahan yang nyata pada parameter lain, maka parameter-parameter tersebut akan dianggap sebagai parameter kunci (key variable). Gambar 10 merupakan grafik hasil uji sensitivitas dari simulasi Powersim.

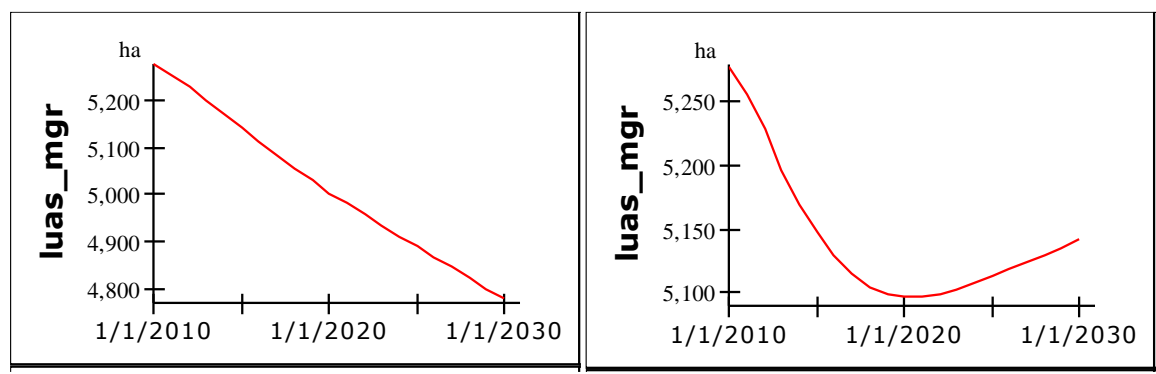

Gambar 10. perbandingan luas mangrove saat parameter kunci dinaikkan $10 \%$.

Gambar 10 menunjukkan adanya peningkatan luas mangrove pada tahun 2020 saat variabel kunci dinaikkan 10\%. Sedangkan Gambar 11 menunjukkan bila variabel kunci diturunkan $10 \%$ maka luas mangrove yang tersisa pada tahun 2030 tinggal 4580.75 ha, menurun dari skenario dasar semula seluas 4 926.28 ha.

Berdasarkan hasil uji sensitivitas tersebut, maka parameter fraksi zona pemanfaatan mangrove, fraksi stok untuk benih budidaya, fraksi alokasi dana pendidikan, dan harga S. serrata, digunakan sebagai parameter yang akan diintervensi sebagai faktor yang berpengaruh pada kondisi yang akan terjadi di masa depan. 

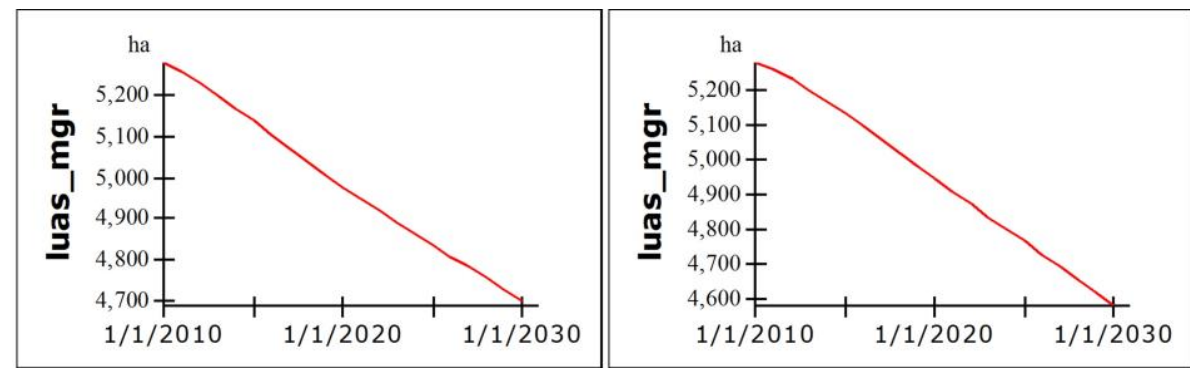

Gambar 11. perbandingan luas mangrove saat parameter kunci diturunkan $10 \%$.

Deskripsi dari masing-masing parameter kunci dan hubungan interkoneksinya dengan parameter yang lain adalah sebagai berikut:

a. Fraksi zona pemanfaatan mangrove adalah kebijakan yang mengatur berapa bagian dari luas mangrove seluruhnya yang dapat digunakan untuk zona pemanfaatan. Dahuri dkk. (2004) mengusulkan 20\% dari kawasan yang dilindungi dapat digunakan untuk pemanfaatan yang berkelanjutan. Kebijakan ini dapat dilakukan melalui peraturan perundangan.

b. Fraksi stok untuk benih budidaya adalah pembagian dari stok S. serrata total yang digunakan untuk keperluan budidaya. Bagian yang lain adalah stok S. serrata yang dimanfaatkan untuk perikanan tangkap konsumsi (langsung jual). Fraksi stok ini dapat diatur pembagiannya dalam kebijakan kuota perikanan tangkap.

c. Fraksi alokasi dana pendidikan adalah bagian dari pendapatan keluarga yang dialokasikan untuk biaya pendidikan. Umumnya pada keluarga nelayan bagian ini rendah sekali, tidak mencapai $10 \%$ dari pendapatan.

d. Harga S. serrata yang digunakan disini adalah harga S. serrata untuk pasar ekspor.

Tabel 2. Keterkaitan antar parameter dan kondisi (state) untuk skenario kebijakan.

\begin{tabular}{|c|c|c|c|c|}
\hline No & Faktor & \multicolumn{3}{|c|}{ Kondisi di masa mendatang } \\
\hline \multirow[t]{5}{*}{1} & Fraksi zona & $1 \mathrm{~A}$ & $1 \mathrm{~B}$ & $1 \mathrm{C}$ \\
\hline & pemanfaatan & $0 \%$ & $20 \%$ & $40 \%$ \\
\hline & & Tidak ada zona & Sesuai teori yang & Terjadi peningkatan karena \\
\hline & & Pemanfaatan, seperti & berlaku di kalangan & kebutuhan SDA lebih besar, \\
\hline & & kondisi saat ini & akademisi saat ini & $\begin{array}{l}\text { sehingga ada kebijakan } \\
\text { peningkatan luas zona } \\
\text { pemanfaatan mangrove }\end{array}$ \\
\hline \multirow[t]{3}{*}{2} & Fraksi stok untuk & $2 \mathrm{~A}$ & $2 \mathrm{~B}$ & $2 \mathrm{C}$ \\
\hline & benih budidaya & $0 \%$ & $40 \%$ & $60 \%$ \\
\hline & & $\begin{array}{l}\text { Tidak ada stok untuk } \\
\text { sylvofishery }\end{array}$ & $\begin{array}{l}\text { Peningkatan fraksi } \\
\text { untuk budidaya }\end{array}$ & $\begin{array}{l}\text { Lebih diutamakan stok untuk } \\
\text { benih budidaya, karena lebih } \\
\text { menguntungkan }\end{array}$ \\
\hline \multirow[t]{3}{*}{3} & Fraksi alokasi & $3 \mathrm{~A}$ & $3 B$ & $3 \mathrm{C}$ \\
\hline & dana pendidikan & $10 \%$ & $15 \%$ & $20 \%$ \\
\hline & & $\begin{array}{l}\text { Alokasi menurun } \\
\text { karena pendapatan } \\
\text { berkurang }\end{array}$ & Tetap seperti saat ini & $\begin{array}{l}\text { Pendapatan yang diperoleh dari } \\
\text { pemanfaatan S. serrata } \\
\text { meningkat }\end{array}$ \\
\hline \multirow[t]{3}{*}{4} & Harga S. serrata & $4 \mathrm{~A}$ & $4 \mathrm{~B}$ & $4 \mathrm{C}$ \\
\hline & & Menurun & tetap & Meningkat \\
\hline & & $\begin{array}{l}\text { Preferensi konsumen } \\
\text { menurun }\end{array}$ & $\begin{array}{l}\text { Tetap seperti kondisi } \\
\text { saat ini }\end{array}$ & $\begin{array}{l}\text { Peningkatan } \\
\text { konsumen }\end{array}$ \\
\hline
\end{tabular}


Skenario kebijakan pemanfaatan sumberdaya S. serrata disusun berdasarkan perkiraan kondisi yang akan terjadi di masa depan. Tabel 2 menyajikan keterkaitan antara parameter kebijakan dengan perkiraan kondisi yang akan terjadi di masa depan. Selanjutnya dari masing-masing kondisi tersebut dilakukan kombinasi yang mungkin terjadi antar berbagai kondisi tersebut. Kombinasi-kombinasi tersebut disusun untuk memperoleh tiga bentuk skenario, yaitu: 1) skenario optimistik, 2) skenario moderat, dan 3) skenario pesimistik (Tabel 3).

Jenis skenario untuk kebijakan pemanfaatan kepiting bakau S. serrata di habitat mangrove TNK yang dapat disusun lebih dari tiga kombinasi. Namun untuk mencari kondisi yang optimal dari berbagai kondisi, ketiga kombinasi tersebut dipilih sebagai kemungkinan yang paling besar terjadi di masa depan.

Tabel 3. Skenario dan kombinasi antar faktor dan kondisi.

\begin{tabular}{lll}
\hline No. & Skenario & Kombinasi kondisi parameter \\
\hline 1 & Pesimistik & $1 \mathrm{~A}, 2 \mathrm{~A}, 3 \mathrm{~B}, 4 \mathrm{~A}$ \\
2 & Moderat & $1 \mathrm{~B}, 2 \mathrm{~B}, 3 \mathrm{~B}, 4 \mathrm{C}$ \\
3 & Optimistik & $1 \mathrm{C}, 2 \mathrm{C}, 3 \mathrm{C}, 4 \mathrm{C}$ \\
\hline
\end{tabular}

\subsection{Skenario Pesimistik}

Penerapan skenario pesimistis akan memberikan implikasi terhadap sumberdaya sebagai berikut:

1. Terjadi penurunan luas mangrove, hingga tahun 2030 mangrove yang tersisa seluas 4554 ha;

2. Terjadi penurunan stok S. serrata menjadi $9519,93 \mathrm{~kg} / \mathrm{th}$ pada tahun 2030 .

Grafik hasil simulasi skenario pesimistik disajikan pada Gambar 11.
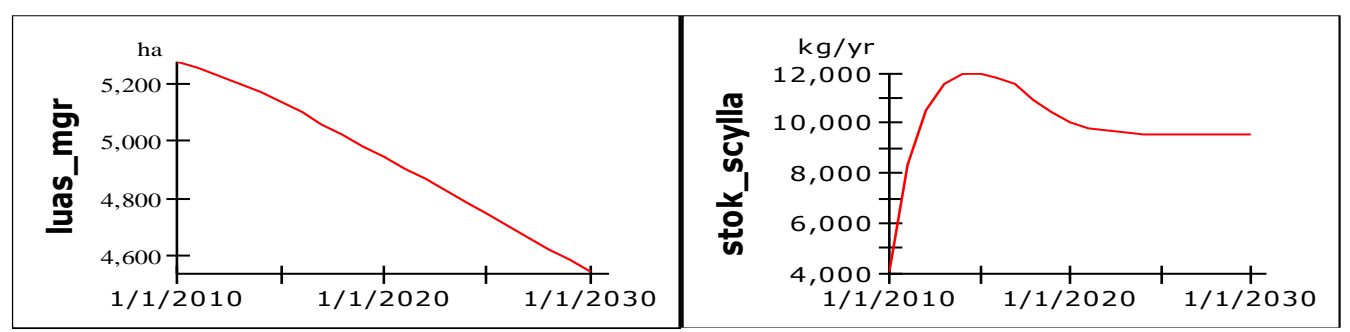

Gambar 11. Grafik hasil simulasi skenario pesimistik.

\subsection{Skenario Moderat}

Penerapan skenario moderat akan memberikan implikasi terhadap sumberdaya sebagai berikut:

1. Mangrove yang awalnya seluas 5277.79 ha tahun 2010, mengalami penurunan luas hingga 5134.56 ha pada tahun 2018, namun setelah itu terjadi peningkatan lagi hingga menjadi seluas 5236.33 ha tahun 2030;

2. Terjadi penurunan stok S. serrata menjadi $10030,98 \mathrm{~kg} /$ th pada tahun 2030 , namun penurunan ini masih lebih lambat dibanding pada skenario pesimistik.

Grafik hasil simulasi skenario moderat disajikan pada Gambar 12.

\subsection{Skenario Optimistik}

Penerapan skenario optimistik akan memberikan implikasi terhadap sumberdaya sebagai berikut:

1. Mangrove mengalami penurunan luas hingga 5175.42 ha pada tahun 2018 , namun setelah itu terjadi peningkatan lagi hingga menjadi seluas 5288.05 ha tahun 2030, dan menjadi stagnan;

2. Terjadi penurunan stok S. serrata menjadi $10124.32 \mathrm{~kg} / \mathrm{th}$ pada tahun 2030 , penurunan ini lebih lambat dibanding penurunan pada skenario moderat.

Grafik hasil simulasi skenario optimistik disajikan pada Gambar 13. 

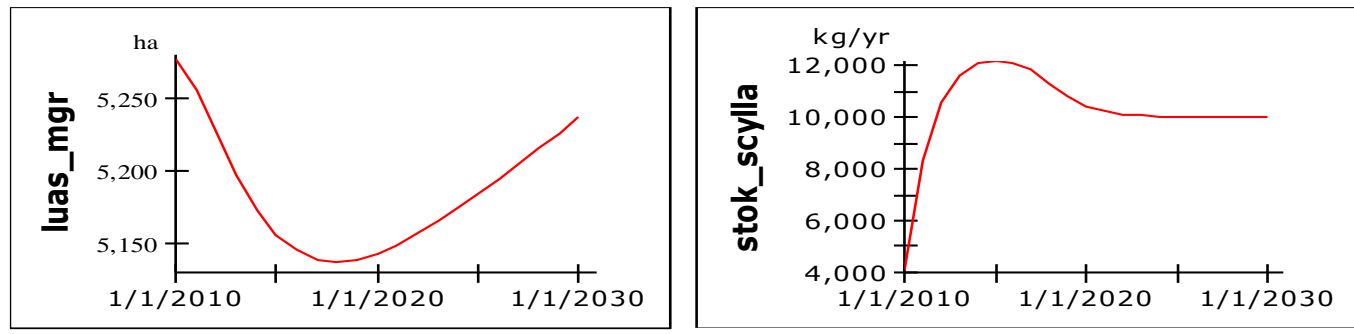

Gambar 12. Grafik hasil simulasi skenario moderat.
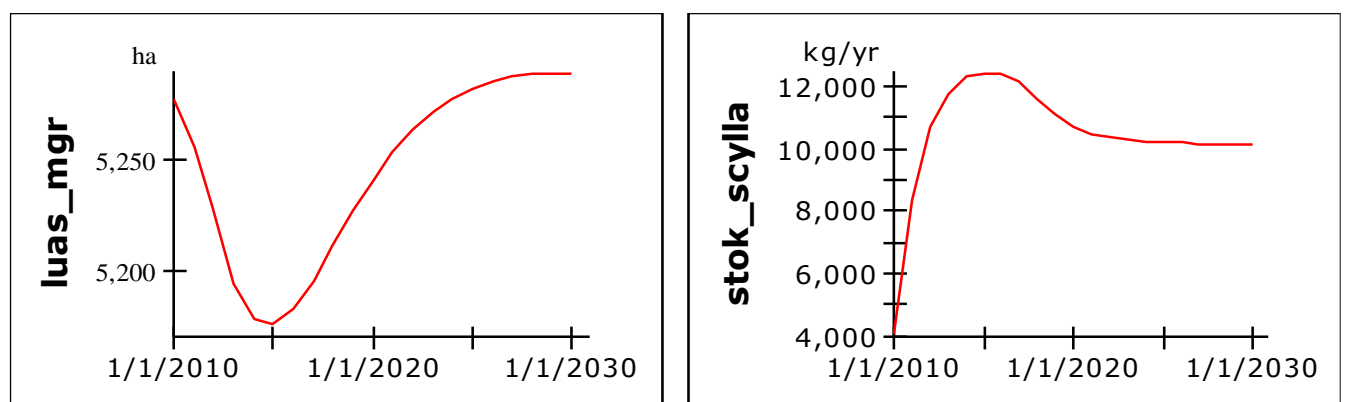

Gambar 13. Grafik hasil simulasi skenario optimistik.

\section{Simpulan dan Saran}

\subsection{Simpulan}

Simpulan yang dapat diambil dari hasil penelitian ini adalah berdasarkan hasil simulasi dengan ketiga skenario, implikasi menunjukkan bahwa skenario optimistik menunjukkan kinerja model yang lebih berkelanjutan untuk pengelolaan hutan mangrove di TNK bila dilakukan dengan pendekatan optimasi pemanfaatan sumberdaya Scylla serrata.

\subsection{Saran}

Model pengelolaan ini dibangun dengan keterbatasan data, terutama yang berkaitan dengan budidaya sylvofishery. Adanya data series yang cukup banyak diharapkan dapat memperbaiki validasi dan kinerja model pengelolaan ini.

\section{Daftar Pustaka}

Arifin, Z. (2006). Carrying Capacity Assessment on Mangrove Forest with Special Emphasize on Mud Crab Sylvofishery System: A Case Studi in Tanjung Jabung Timur District Jambi Province. Tesis. Bogor, Indonesia: Sekolah Pasca Sarjana, Institut Pertanian Bogor.

Dahuri, R., Rais, J., Ginting, S. P., \& Sitepu, M. J. (2004). Pengelolaan Sumberdaya Wilayah Pesisir dan Lautan Secara Terpadu. Jakarta, Indonesia: PT. Pradnyana Paramita.

Ford, A. (1999). Modeling the Environment, An Introduction to System Dynamics Models of Environmental Systems. Washington DC, USA: Island Press.

Gunawan, W., Adinugroho, W. C., Noorcahyati. (2005). Model pelestarian ekosistem mangrove di kawasan Taman Nasional Kutai oleh masyarakat dusun Teluk Lombok. Loka Litbang Satwa Primata, Badan Litbang Kehutanan, Departemen Kehutanan.

Le Vay, L. (2001). Ecology and management of mud crab Scylla spp. Asian Fisheries Science, 14(2), 101-112. 
PHKA-Dephut, NRM/EPIQ, WWF Wallacea \& TNC. (2002). Membangun Kembali Upaya Mengelola Kawasan Konservasi di Indonesia Melalui Majamen Kolaboratif : Prinsip, Kerangka Kerja dan Panduan Implementasi. Naskah kerja teknis PHKA-Dephut, NRM/EPIQ, WWF, Wallacea, TNC

Rohmatulloh. (2008). Studi Dinamika Sistem Penilaian Kinerja Pabrik Gula : Kasus PT PG Rajawali II Unit PG Subang Jawa Barat. Tesis. Bogor, Indonesia: Sekolah Pascasarjana, Institut Pertanian Bogor.

Sparre, P., \& Venema, S. C. (1999). Introduction to tropical fish stock assessment - Part 1: Manual. Dalam Widodo, J., Merta, I. G. S., Nurhakim, S., \& Badrudin, M. (Terj.), Introduksi pengkajian stok ikan tropis - Buku 1: Manual. Jakarta, Indonesia: Pusat Penelitian dan Pengembangan Perikanan. (Buku asli diterbitkan 1998).

Sterman, J. D. (2000). Business Dynamics : System Thinking and Modeling for a Complex World. Boston, USA: Irwin McGraw-Hill.

Triño, A. T., \& Rodriguez, E. M. (2002). Pen culture of mud crab Scylla serrata in tidal flats reforested with mangrove trees. Aquaculture, 211(1-4), 125-134.

UNEP. (2006). Ecosystem-based management: Markers for assessing progress. The Hague, Netherlands: United Nations Environment Programme.

Van der Lee, G. E., Van der Molen, D. T., Van den Boogaard, H. F., \& Van der Klis, H. (2006). Uncertainty analysis of a spatial habitat suitability model and implications for ecological management of water bodies. Landscape Ecology, 21(7), 1019-1032. 